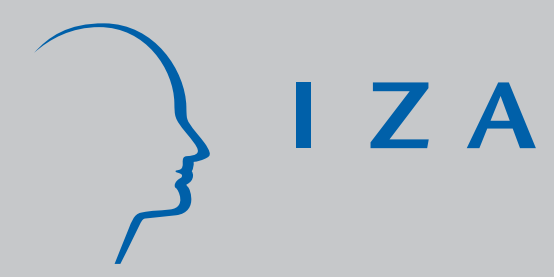

IZA DP No. 1729

Social Security Incentives, Human Capital Investment and Mobility of Labor

Panu Poutvaara

August 2005 


\title{
Social Security Incentives, Human Capital Investment and Mobility of Labor
}

\author{
Panu Poutvaara
}

University of Helsinki, CEBR, CESifo, HECER and IZA Bonn

Discussion Paper No. 1729

August 2005

\author{
IZA \\ P.O. Box 7240 \\ 53072 Bonn \\ Germany \\ Phone: +49-228-3894-0 \\ Fax: +49-228-3894-180 \\ Email: iza@iza.org
}

\begin{abstract}
Any opinions expressed here are those of the author(s) and not those of the institute. Research disseminated by IZA may include views on policy, but the institute itself takes no institutional policy positions.

The Institute for the Study of Labor (IZA) in Bonn is a local and virtual international research center and a place of communication between science, politics and business. IZA is an independent nonprofit company supported by Deutsche Post World Net. The center is associated with the University of Bonn and offers a stimulating research environment through its research networks, research support, and visitors and doctoral programs. IZA engages in (i) original and internationally competitive research in all fields of labor economics, (ii) development of policy concepts, and (iii) dissemination of research results and concepts to the interested public.
\end{abstract}

IZA Discussion Papers often represent preliminary work and are circulated to encourage discussion. Citation of such a paper should account for its provisional character. A revised version may be available directly from the author. 


\section{ABSTRACT \\ Social Security Incentives, Human Capital Investment and Mobility of Labor ${ }^{*}$}

Migration between countries with earnings-related and flat-rate pay-as-you-go social security systems may change human capital investments in both countries. The possibility of emigration boosts investments in human capital in the country with flat-rate benefits. Correspondingly, those expecting to migrate from the country with earnings-related benefits to a country with flat-rate benefits may reduce their investment in education. With suitably planned transfers between the two countries, allowing for migration may generate a Paretoimprovement for all current and future generations. Without transfers, either country may be unable to pay for promised benefits when labor becomes mobile.

JEL Classification: H55, I2, F22

Keywords: $\quad$ social security, education, migration, earnings-related and flat-rate pensions

Corresponding author:

Panu Poutvaara

Department of Economics

P.O. Box 17 (Arkadiankatu 7)

FIN-00014 University of Helsinki

Finland

Email: panu.poutvaara@helsinki.fi

\footnotetext{
* Comments received at presentations at the Occasional Seminar at the DG Employment, Social Affairs and Equal Opportunities in Brussels in January 2005, at the Annual Meeting of Finnish Economists in Maarianhamina in February 2005, and at the CEBR/CESifo Conference on Pension Reform in Copenhagen in June 2005 are gratefully acknowledged. In particular, I wish to thank Markus Haavio, Katarina Keller, Marko Köthenbürger, Mikko Puhakka, Harrie Verbon, and Andreas Wagener. I acknowledge financial support from the Danish Social Science Research Council, without implicating the sponsor for the views expressed.
} 


\section{Introduction}

Pensions are the single largest government transfer program in the European Union. In 2001, the then 15 EU member states spent on average 8.8 percent of their GDP on public retirement benefits (OECD, 2003). Pension policies have traditionally been viewed as a domain of nation-states and, correspondingly, there are wide differences in how benefits are determined. In Continental Europe, like France, Germany, and Italy, pensions are viewed as postponed wage income and their aim is to smooth lifetime consumption. In such "Bismarckian" programs, retirement benefits are linked to past earnings. In the competing "Beveridgean" tradition, retirement benefits are used to protect the elderly against poverty. Benefits are then rather flat, with the link to past earnings weak or even nonexistent. These rather flat-rate systems dominate, or at least play an important part, in public pensions in Denmark, Ireland, the Netherlands, and the United Kingdom (Disney, 2004). Both earnings-related and flat-rate pensions are mainly organized according to payas-you-go (PAYG) principle, implying that the benefits of the current retirees are paid by current workers. ${ }^{1}$

Migration may endanger both earnings-related and flat-rate pension systems. With migration, intragenerational redistribution of flat-rate systems generates an adverse selection problem. Earnings-related systems, on the other hand, may benefit from the inflow of highincome contributors. The intergenerational redistribution component, on the other hand, poses a more severe challenge to earnings-related systems as these are larger. ${ }^{2}$ In 2001 , public spending on retirement benefits was on average 6.4 percent of GDP in OECD countries with flat-rate benefits, and 9.4 percent in countries with earnings-related benefits (Disney, 2004; OECD, 2003).

Social security rules and migration possibilities also influence incentives to invest in human capital. An option to migrate to a country with less redistributive social security system increases the expected private return to human capital, thus boosting such investments. When young people do not know beforehand how mobile they are going to be, the investments of those who finally remain change. Such uncertainty about one's own future mobility may result from uncertainties related to family formation, future partnership status, and on random events related to employment.

This paper takes a dynamic view of economic integration and the challenges it poses to social security systems of different types. There are two countries, one with earningsrelated benefits, and another with flat-rate benefits. The two countries may differ also in social security contribution rates, and both have organized their social security system on a PAYG-basis. At the starting point, there is no migration. Then labor becomes mobile, corresponding to tighter integration. Since production technologies are identical in both countries, migration does not affect the productivity of human capital stock of the migrant. This paper asks two questions. The first one is how the possibility of migration affects

\footnotetext{
${ }^{1}$ Some countries, like the Netherlands, also have a prominent funded part of social security. This paper focuses on PAYG systems.

${ }^{2}$ The average rate of return offered by the PAYG system equals only the growth rate of the economy, which always falls short of the market interest rate (Aaron 1966). The lower rate of return that the PAYG systems offer can be interpreted as an interest payment on the implicit debt, which was created when older cohorts were paid pensions, even when they had not previously contributed to the system.
} 
incentives to invest in human capital and economic well-being in the two countries. The second question is whether both social security systems can be maintained after the labor markets have been integrated.

The main findings are the following. Assume first that neither country has a social security system that would be preferred by all citizens. Then allowing for migration would increase the investment in human capital at the upper echelon of productivity distribution in the country with flat-rate benefits, and decrease investment in human capital at the lower levels of productivity in the country with earnings-related benefits. Thus, allowing migration would increase human capital formation in the country with flat-rate benefits, and reduce human capital formation in the country with earnings-related benefits. The effects on the stock of human capital in both countries after migration would depend on the productivity distribution, and on the social security contribution rates.

Assume next that the two countries have the same social security contribution rate, and that all citizens have the same innate ability. Then allowing for migration poses a challenge only to the country with flat-rate benefits. This country would lose workers immediately after allowing for migration, at the same time as it would still face obligations towards its elderly beneficiaries. The most striking finding is that this need not pose a problem in the dynamic context, provided that there are transfers between the two countries. In such coordinated solution, the citizens belonging to each cohort of both countries would be strictly better off, provided that there is initially a transfer from the country with earnings-related benefits to the country with flat-rate benefits, and in subsequent periods a transfer from the country with flat-rate benefits to the country with earnings-related benefits.

This paper is organized as follows. Section 2 reviews the literature. Section 3 develops the model. Section 4 presents the results concerning investment in human capital and migration. Section 5 analyzes welfare effects. Section 6 concludes.

\section{Literature Review}

European social insurance and public pension systems create considerable incentives to migrate. Wildasin (1999) uses data on public pension contributions and benefits to estimate the change in the present value of lifetime wealth for "representative workers" in seven EU countries, finding that migrants may experience changes in public pension wealth, up to 25 percent of lifetime wealth. Homburg and Richter (1993) and Breyer and Kolmar (2002) analyze the efficiency of national flat-rate pension systems when labor is mobile. The effects of migration on competition between Bismarckian and Beveridgean social insurance systems has been analyzed by Cremer and Pestieau (2003). They focus on intragenerational redistribution, instead of pensions. Most closely related to this paper, Kolmar (forthcoming) analyzes migration between two countries, one with a flat-rate and another with an earnings-related system. In his contribution, each country contains high-skilled and low-skilled individuals. The size of these two groups and their wages grow at exogenous country-specific rates. All of these earlier contributions take productivity as given, while this paper endogenizes it.

The effects of social security incentives on human capital investment have received surprisingly little attention. Lau and Poutvaara (2001) present a theoretical model of the effects of social security incentives on human capital investment, in the absence of migration and with a zero interest rate. Jensen et al. (2004) present a computational general equilibrium 
model of human capital formation, labor supply and retirement, under alternative social security rules. They find that social security rules have a considerable impact on retirement behavior and welfare. Even low-productivity workers would prefer earnings-related benefits, if productivity differences are sufficiently low. Neither Lau and Poutvaara (2001) nor Jensen et al. (2004) include mobility.

There is an extensive literature on the effects of the mobility of labor on investment in education. Justman and Thisse (1997) and Wildasin (2000) analyze the effects of migration on public provision of education. Analyzing migration from poor to rich countries, Grubel and Scott (1966) and Bhagwati and Hamada (1974) highlight the losses that emigration imposes on source countries. Contrary to their results, Mountford (1997) and Stark et al. (1997) show that some migration from developing countries to developed countries may actually benefit the country of origin. A possibility to migrate to a richer country increases the expected return to human capital investment in a poor country, thus encouraging private investment. Even with part of high-skilled workers migrating, this initial brain gain may dominate, so that the less developed country can end up with a higher average level of human capital per worker with migration than without it. Mountford (1997) and Stark et al. (1997) study the use of migration quotas by less developed countries. This paper assumes that there are no legal restrictions to migration, consistent with the EU principles of free mobility. Furthermore, this paper allows migration in both directions. None of these earlier contributions include social security.

\section{The Model}

Two countries, labelled A and B, form a common labor market at the beginning of period 1. Both countries are populated by overlapping generations of citizens. Each citizen lives for two periods, becoming educated, possibly migrating and working in the first period and being retired and collecting social security benefits in the second period. Citizens become educated in their country of birth at the beginning of the first period of their life. They learn whether they are mobile or not after completing education. That the actual realization of mobility is disclosed only after completing education may reflect, for example, realized language and cultural skills, social networks, and family formation. The probability of being mobile is $p$, and those mobile can migrate costlessly. Any shocks to the value of $p$ are revealed at the beginning of the period, before investments in education are made. The next section solves how changes in $p$ affect investment in education in the two countries. After that, welfare effects of changes are analyzed focusing on the effects of the formation of the common labor market when initially $p=0$, and as a result of the shock $p$ becomes positive. This is without loss of generality. All results would hold qualitatively for a discrete increase in $p$ also in case $p$ is initially positive.

The two countries differ in their social security system. In country A, the social security system is earnings-related. Workers pay in every period $t$ social security contributions at rate $\tau_{A}$, and receive in the following period as social security benefits a fraction $x_{t+1}$ of their previous earnings. This fraction is determined endogenously to balance the government budget. In country $\mathrm{B}$, the social security contribution rate is $\tau_{B}$ and social security benefits to the elderly are flat-rate, and of size $b_{t}$ in period $t$. All workers receive pension benefits from the country where they worked. This implies that the results would hold whether the 
retired stay in the country where they worked, or return to their home country. In both countries, the social security system is organized on a PAYG basis.

Citizens may differ in their productivity. Human capital is a joint product of innate ability and education. For a citizen with ability $a$ and individual effort $e_{t}$ in period $t$, the individual human capital stock is

$$
h\left(a, e_{t}\right)=a+e_{t} .
$$

The monetarized cost of effort $e_{t}$ is $\frac{1}{2} e_{t}^{2}$, which may include both psychological disutility and private resource costs for tuition and books. This formulation of an increasing marginal cost guarantees a bounded investment in $e$. Ability $a$ follows the same distribution in both member states. The innate ability is distributed between zero and $\bar{a}$, with density function $f(a)$. The utility of the educated is in both periods linear in their consumption, net of the cost of investment in education. The individuals have access to perfect capital markets at the internationally determined interest rate $r$, corresponding also to the individual discount rate. The pre-migration younger population to become educated is of the same size in A and B, and normalized to one. Production technologies are identical in both countries, combining capital and labor with constant elasticies to scale. The wage rate is normalized to unity reflecting the fact that the wage rate is fixed in a small open economy by the international mobility of physical capital.

Importantly, pre-migration cohort sizes remain the same in each country even with migration. One interpretation of this is that migration is concentrated among those citizens without children. If this is the case, then those who become mobile would be a subset of citizens without children. Pre-migration cohorts of both countries could still remain constant. Alternatively, we could think that migration is only temporary, and that citizens then receive pension benefits from both countries in relation to how long they have worked in each country. In that case, they would return to their home country before their children invest in their education. Either interpretation would result in qualitatively similar results. The remainder of the paper is written under the implicit assumption that migrants are a subset of those citizens without children, but all the results would hold also if migration would be temporary and citizens would then receive pension benefits from both countries in relation to how long they have spent in each country.

\section{Social Security and Investment in Education}

\subsection{No migration}

In country $\mathrm{A}$, a citizen with ability a chooses private investment in effort to maximize his or her lifetime disposable income, solving

$$
\max _{e_{t}}\left(-\frac{1}{2} e_{t}^{2}+\left(1-\tau_{A}\right)\left(a+e_{t}\right)+\frac{x_{t+1}^{e}\left(a+e_{t}\right)}{1+r}\right) .
$$

Here $x_{t+1}^{e}$ denotes the expected replacement rate in the following period. This results in private investment in effort

$$
e_{A, t}=1-\tau_{A}+\frac{x_{t+1}^{e}}{1+r} .
$$


In a steady-state equilibrium, $x_{t+1}^{e}=x_{t}$ and also $e_{A, t}$ is constant and independent of ability. In period $t$, the budget balance of the social security system then reads as

$$
\tau_{A} \int_{0}^{\bar{a}}\left(a+e_{A, t}\right) f(a) d a=x_{t} \int_{0}^{\bar{a}}\left(a+e_{A, t-1}\right) f(a) d a .
$$

The left-hand side reports social security contributions and the right-hand side benefits, as a function of past earnings. Given that $e_{A, t}=e_{A, t-1}$ with constant $\tau_{A}$ and $x_{t+1}^{e}=x_{t}$, the social security budget is balanced only when $x_{t}=\tau_{A}$. The equilibrium private investment in education is then

$$
e_{A, t}=1-\frac{r \tau_{A}}{1+r} .
$$

Correspondingly, private investment in education in country B solves

$$
\max _{e_{t}}\left(-\frac{1}{2} e_{t}^{2}+\left(1-\tau_{B}\right)\left(a+e_{t}\right)+\frac{b_{t+1}^{e}}{1+r}\right)
$$

resulting in private investment in effort

$$
e_{B, t}=1-\tau_{B}
$$

Note that as country B has lump-sum benefits, only the social security contribution rate but not the lump-sum benefit affects investment in education. The government budget constraint yields in the steady-state without migration

$$
b_{t}=\tau_{B} \int_{0}^{\bar{a}}\left(a+1-\tau_{B}\right) f(a) d a .
$$

\subsection{Common labor market}

The timing of individual actions except for saving and consumption in a common labor market is presented as Fig. 1. Individual decisions are characterized backwards. That is, migration decisions are first presented for arbitrary investments in education, and the optimal investments in education are then studied taking subsequent migration decisions as given.

After learning their mobility status, mobile citizens choose the member state to maximize the net present value of their remaining lifetime disposable income. Given perfect capital markets, this also maximizes their utility. A mobile citizen migrates from member state A to $\mathrm{B}$ if and only if

$$
\left(1-\tau_{B}\right)\left(a+e_{t}\right)+\frac{b_{t+1}^{e}}{1+r}>\left(1-\tau_{A}+\frac{x_{t+1}^{e}}{1+r}\right)\left(a+e_{t}\right) .
$$

Correspondingly, a mobile citizen migrates from member state $\mathrm{B}$ to $\mathrm{A}$ if and only if

$$
\left(1-\tau_{A}+\frac{x_{t+1}^{e}}{1+r}\right)\left(a+e_{t}\right)>\left(1-\tau_{B}\right)\left(a+e_{t}\right)+\frac{b_{t+1}^{e}}{1+r} .
$$

When deciding on their investment in education, citizens form expectations on whether they would like to migrate, in case they become mobile. For example, a citizen with low ability 


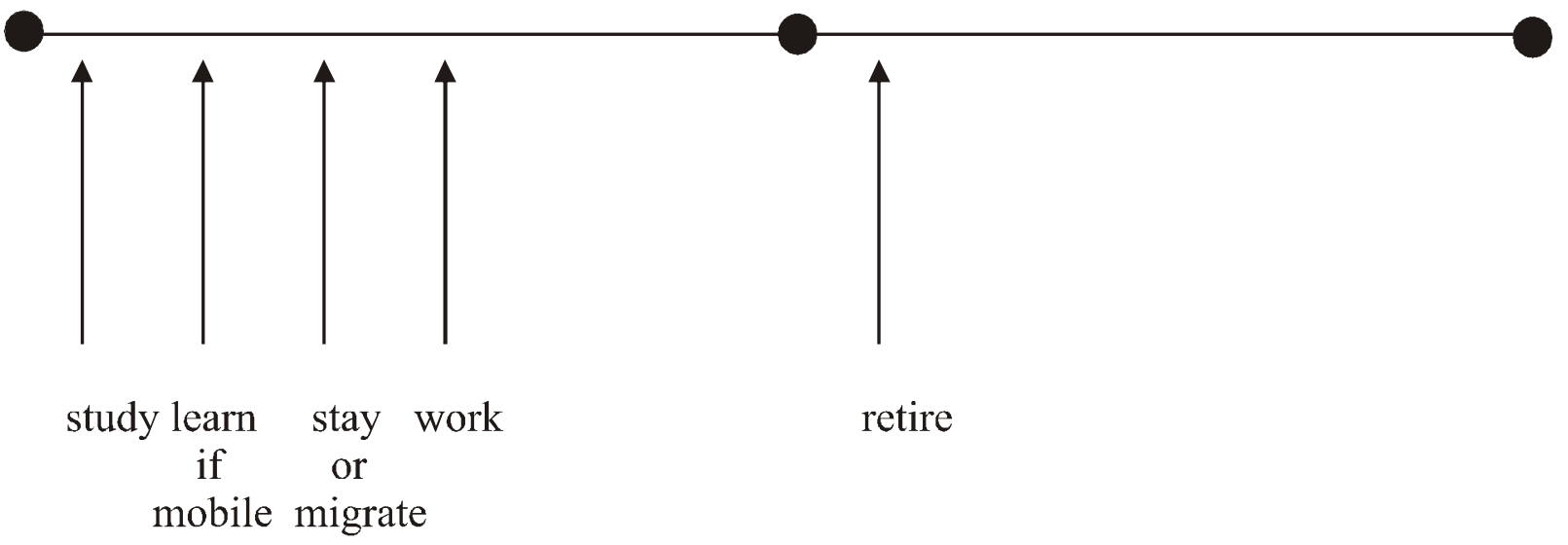

Figure 1: Timing with mobility.

may always prefer a member state with lump-sum benefits. For those planning to always stay in their home country, investment in education depends on the contribution rate and benefits as when migration is not possible. It remains to characterize investments in case a citizen plans to migrate, if feasible. The maximization problem of a citizen who would like to migrate from country A to country B reads as

$$
\max _{e_{t}}\left(-\frac{1}{2} e_{t}^{2}+(1-p)\left(1-\tau_{A}+\frac{x_{t+1}^{e}}{1+r}\right)\left(a+e_{t}\right)+p\left(1-\tau_{B}\right)\left(a+e_{t}\right)+\frac{p b_{t+1}^{e}}{1+r}\right),
$$

resulting in an optimal investment

$$
\widetilde{e}_{A, t}=(1-p)\left(1-\tau_{A}+\frac{x_{t+1}^{e}}{1+r}\right)+p\left(1-\tau_{B}\right) .
$$

Here tilde is used to denote the choice by a citizen willing to migrate. A potential migrant from country B to country A optimizes

$$
\max _{e_{t}}\left(-\frac{1}{2} e_{t}^{2}+p\left(1-\tau_{A}+\frac{x_{t+1}^{e}}{1+r}\right)\left(a+e_{t}\right)+(1-p)\left(1-\tau_{B}\right)\left(a+e_{t}\right)+\frac{(1-p) b_{t+1}^{e}}{1+r}\right),
$$

with the solution

$$
\widetilde{e}_{B, t}=p\left(1-\tau_{A}+\frac{x_{t+1}^{e}}{1+r}\right)+(1-p)\left(1-\tau_{B}\right) .
$$

Whatever the ability distribution and the willingness to migrate, it has to hold that $x_{t+1}^{e}=\tau_{A}$ in the steady-state. Otherwise, the budget constraint stating that contributions collected equal benefits paid in each period would not be satisfied. When $x_{t+1}^{e}=\tau_{A}$, (3) and (5) imply that investments in education by those expecting to migrate are a linear combination of investments chosen in the two countries in the absence of migration, with $p$ determining the weights:

$$
\begin{aligned}
& \widetilde{e}_{A, t}=(1-p) e_{A, t}+p e_{B, t}, \\
& \widetilde{e}_{B, t}=p e_{A, t}+(1-p) e_{B, t} .
\end{aligned}
$$


Focusing on the steady-state, we find that

Proposition 1 With $x_{t+1}^{e}=\tau_{A}$, there is migration from country $A$ to country $B$ if and only if

$$
b_{t+1}^{e}>\frac{1+r}{2}\left(e_{A, t}-e_{B, t}\right)\left[(2-p) e_{A, t}+p e_{B, t}\right]
$$

and from country $B$ to country $A$ if and only if

$$
b_{t+1}^{e}<\frac{1+r}{2}\left(e_{A, t}-e_{B, t}\right)\left[2 \bar{a}+(2-p) e_{B, t}+p e_{A, t}\right] .
$$

Proof. In the Appendix.

The first (second) condition in Proposition 1 states that a citizen with the lowest (highest) ability would like to emigrate from the country with earnings-related (flat-rate) benefits when the expected flat-rate benefit is sufficiently high (low). A necessary, though not sufficient, condition for having migration from country $\mathrm{B}$ to $\mathrm{A}$ is that $e_{A, t}>e_{B, t}$, which is equivalent to

$$
\frac{r \tau_{A}}{1+r}<\tau_{B}
$$

This corresponds to a requirement that the effective tax burden caused by the social security contribution rate has to be higher in the country with flat-rate benefits. Notice that this may be the case even when the contribution rate is lower with flat-rate system. ${ }^{3}$ If (14) is violated, then everyone would prefer to migrate from country A to B. We can also show

Proposition 2 An increase in the probability of international mobility $p$ decreases (increases) investment in education in country $A(B)$, provided that there is emigration.

Proof. In the Appendix.

We find that the possibility of migration tends to stimulate investment in education in the country with flat-rate benefits, and depress it in the country with earnings-related benefits. The caveat that the results hold provided that there is emigration results as migration may go in only one direction, in which case changes in $p$ would not affect investment in education in the country with no emigration.

\section{Welfare Effects of Migration}

\subsection{Effects on steady-state generations}

We can separate between two qualitatively different migration patterns. With population exchange, a fraction of citizens from either country would prefer to migrate to the other country. With unilateral migration, only citizens from one country want to emigrate.

Population exchange requires that the high-ability citizens want to migrate from country B to country A, and low-ability citizens want to migrate from A to B. A necessary condition

\footnotetext{
${ }^{3}$ Assuming an annual interest rate of 4.0 percent and that each period consists of 30 years would imply $r=2.24$. (14) is fullfilled if $\tau_{b}$ is at least 69 percent of $\tau_{a}$. In 2001, public spending on retirement benefits was in average 6.4 percent of GDP in OECD countries with flat-rate benefits, and 9.4 percent in countries with earnings-related benefits (Disney, 2004; OECD, 2003). That the average $\tau_{b}$ in OECD countries is 68 percent of the average $\tau_{a}$ suggests that the condition holds for many but not all country pairs.
} 
for population exchange is that (14) holds. This implies that citizens invest more in their education the higher the probability that they would reside in country A. As a result, allowing for migration resulting in population exchange discourages investment in education among low-ability people in country A, and encourages it in country B among high-ability people. The welfare effects on steady-state cohorts are given by

Proposition 3 Migration resulting in population exchange increases the expected utility of high-ability natives in country $B$ and low-ability natives in country A. The utility of lowability natives in country $B$ may change in either direction. The utility of high-ability natives in country $A$ is left unchanged.

Proof. In the Appendix.

A priori, one could expect that population exchange would always hurt low-ability citizens of the country with flat-rate benefits. After all, population exchange means an outflow of net contributors, and an inflow of those expected to benefit from income redistribution. The most surprising finding of proposition 3 is that the effects of migration on the welfare of low-ability citizens in country B may go in either direction. They face two conflicting effects. The above mentioned effect, an outflow of net contributors and an inflow of other low-ability citizens, could be labelled a redistribution effect. It reduces the welfare of low-ability citizens in country B. However, there is also a human capital effect. The possibility of migration to a country with earnings-related benefits encourages investment in education by high-ability natives. At the same time, the low-ability immigrants have invested more in human capital as they also have taken into account the possibility that they would not have become mobile. This human capital effect may overweight the redistribution effect.

With unilateral migration, we find that

Proposition 4 If all citizens want to migrate from $B$ to $A$, then allowing for migration improves the steady-state welfare of the initial citizens in $B$ and leaves the steady-state welfare of the initial citizens in A unchanged.

Proof. When all citizens want to migrate and fraction $p$ emigrates, the distribution of $a$ does not change. By Proposition 2, allowing for migration from B to A increases investment in education in B. This implies a higher steady-state $b$. By revealed preferences, this implies that the expected utility of all citizens in B increases: each of them could have chosen the same investment in education as without migration and received a higher benefit.

\subsection{Effects on transition generations}

The previous section showed that allowing for migration may improve the welfare of steady-state generations in both countries, even when the two countries have identical production technologies. However, an intergenerational Pareto-improvement would also require that the welfare of the transition generation is improved in both countries, or at least left unchanged. This section analyzes whether this can be the case. For simplicity, we assume that the two countries have identical social security contribution rates so that $\tau_{A}=\tau_{B}=\tau$. Assume also that $\tau<\frac{1}{2}$ as otherwise reducing $\tau$ would increase social security tax revenue 
in country B also without migration. Also, assume that the citizens are of identical abilities, $a$ being normalized to zero. In the absence of migration, flat-rate benefits are then

$$
b^{N}=\tau(1-\tau)
$$

We can now calculate the surplus (or deficit) with promised benefits in country A (B) in period $t$, denoted by $S_{A, t}\left(S_{B, t}\right)$. It is the sum of social security contributions collected in country $\mathrm{A}(\mathrm{B})$ in period $t$, deducted by the sum of promised benefits to the pensioners living in country A (B) in period $t$ if $x_{t}=\tau_{t}\left(b_{t}=b^{N}\right)$.

As shown in the proof of the following proposition, the transition generation of pensioners in $\mathrm{B}$ would lose from allowing migration if there are no transfers between the two countries. However, the next proposition also shows that there is a transfer program which allows for an intertemporal Pareto-improvement in both countries with migration, compared with the situation without migration. To show this, we first define:

Definition 1 Surplus-Sharing Mechanism requires that

(i) if $S_{A, t}+S_{B, t} \geq 0$, then both countries pay their promised benefits and any remaining surplus is distributed to all citizens of $A$ and $B$ as uniform lump-sum transfers;

(ii) if $S_{A, t}+S_{B, t}<0$ and $S_{A, t} \geq 0$ then $A$ pays benefits with $x_{t}=\tau_{A}$ and transfers the surplus to $B$;

(iii) if $S_{A, t}+S_{B, t}<0$ and $S_{B, t} \geq 0$ then $B$ pays benefits with $b_{t}=b^{N}$ and transfers the surplus to $A$.

Surplus-Sharing Mechanism requires solidarity between the two countries in financing their promised benefits to the extent that neither country is required to make transfers to the point where it would not be able to pay its own promised benefits. Any surplus which is left after both countries have financed their promised benefits is distributed to all citizens as lump-sum transfers. This is a rather demanding condition for finding a Paretoimprovement: using the surplus to reduce social security contribution rates or to pay supplementary earnings-related benefits would result in lower distortions in human capital formation and thus to even higher welfare. However, an intertemporal Pareto-improvement is possible already with Surplus-Sharing Mechanism:

Proposition 5 With homogeneous population, equal contribution rates, and Surplus-Sharing Mechanism, both earnings-related and flat-rate benefits can be paid in both countries with migration as in the absence of migration. Together, countries $A$ and $B$ have a total surplus of $S_{A, t}+S_{B, t}=\frac{\tau^{2} p}{1+r}$ in the period of transition and $S_{A, t}+S_{B, t}=\frac{\tau^{2} p(1-p)}{1+r}$ in the new steadystate. In the absence of transfers, country $A$ would run a surplus and country $B$ a deficit in the transition period. In the new steady-state, country $A$ would have a balanced budget and country $B$ a surplus.

Proof. In the Appendix.

Notice that Proposition 5 and Surplus-Sharing Mechanism identify only one way of achieving an intertemporal Pareto-improvement in both countries. As lump-sum transfers are independent of domicile, they do not affect migration decisions or investments in 
education. The finding that $S_{B, t}<0$ in the transition period implies that there is no Paretoimprovement in the absence of transfers; country B would not be able to pay as high benefits to the pensioners of the transition generation as it would without migration. Intuitively, the required transfer mechanism reflects the role of the PAYG social security as implicit government debt. When migration is allowed, a fraction of current and future human capital migrates to the country with earnings-related benefits. This reduces the current and future tax base in the country with flat-rate benefits, as well as the number of beneficiaries in future. However, the current number of beneficiaries is determined by history. Therefore, the country with flat-rate benefits ends up under duress in the first period with a common labor market. This problem can be solved by transferring tax payments of the first generation of migrants.

The policy coordination discussed in this paper is linked to, yet separate, from previous proposals by Sinn (1994) and Richter (2002). In the Origin Principle suggested by Sinn (1994), young citizens would have to choose their redistribution system at the young age without possibility to escape it later. In the framework of this paper, this would be equivalent to having a probability of being able to change from one system to another equal to one. This would eliminate the positive human capital effect from increased human capital investments of those potential migrants staying; everyone who would like to change the system would choose in the first place the social security system of the other country.

In the Principle of Delayed Integration that Richter (2002) proposes, migrants would be reassigned in the matters of social security and income redistribution from their previous country to the new country only after a transition period. During the transition period, they would be subject to the rules of their previous country of residence. There are two alternative interpretations of this to social security. The first one is that migrants would both make their payments and receive their benefits partly from their country of origin, and partly from the country of destination. The second one is that they would contribute for a certain time to the system of their country of origin and then make remaining payments and collect their benefits from the country to which they have migrated. The first interpretation of the Principle of Delayed Integration would effectively reduce both gains and losses from migration, corresponding in its effects to scaling down the probability of mobility. The second interpretation, on the other hand, could result in qualitatively different distribution of welfare gains and losses. Take, for example, the case of identical contribution rates and abilities analyzed in this subsection. Having migrants from B to A pay a fraction of their contributions to $\mathrm{B}$, yet receive benefits from $\mathrm{A}$, would introduce a permanent flow of funds from A to B. After the transition period, this would require country A to scale down its replacement rate. Therefore, the transfer system suggested in this paper could allow for an intertemporal Pareto-improvement, even if a permanent system of Delayed Integration would not.

\section{Conclusion}

This paper derived some expected and some rather surprising results on the effects of allowing migration between countries with different social security systems. As expected, there is some cutoff productivity level above which citizens prefer earnings-related systems, and below which they would rather have flat benefits. This cutoff level may also be associated 
with a corner solution, with all citizens preferring one of the competing systems. Also, it turned out that the possibility of migration from a flat-rate system to an earnings-related system stimulates human capital formation. Conversely, those willing to migrate to a country with flat-rate benefits may reduce their investment in education.

Allowing for free migration may, but need not, pose problems for either system. Perhaps the most surprising result is that allowing for migration could generate an intertemporal Pareto-improvement even in the absence of any productivity differences between the two countries, unilateral migration and the two countries having identical social security contribution rates. This requires transfers between the countries. If the two countries share the surplus left when they both pay benefits as without migration, then the transfers go in opposite directions in the transition period and in the new steady-state. In the transition period, the first cohort of migrants from the country with flat-rate benefits pays part of their social security contributions to their country of origin, even if they receive benefits from their new home country. In subsequent periods, the country with flat-rate benefits can transfer resources to the country with earnings-related benefits in return, and still have its citizens reach a higher expected utility. This effect would not arise in the absence of endogenous human capital formation, highlighting the importance of taking into account investments in education when analyzing the welfare effects of labor market integration.

\section{Appendix. Proofs}

\section{Proof of Proposition 1.}

The presence of migration requires that two conditions are satisfied: First, those migrating have to be willing to migrate ex post. Second, those willing to migrate have to reach ex ante a higher expected utility with the strategy in which they invest in education expecting to be willing to migrate than by investing as they would when not expecting to migrate. The first condition is implied by the second one, as there is no uncertainly related to whether migration is attractive after the individual's own mobility status is revealed. To analyze the second condition, we have to solve for the expected utility of those most likely to migrate. They are citizens with $a=0$ in country A and citizens with $a=\bar{a}$ in B. Inserting (3), $x_{t+1}^{e}=\tau_{A}$, and $a=0$ into (2) gives as the utility of those with $a=0$ and not planning to migrate $\frac{1}{2} e_{A, t}^{2}$. Inserting $x_{t+1}^{e}=\tau_{A},(3),(5)$, and (12) into (8), we find that the utility of those citizens with $a=0$ and wishing to migrate from $\mathrm{A}$ to $\mathrm{B}$ is

$$
\frac{1}{2}\left[(1-p) e_{A, t}+p e_{B, t}\right]^{2}+\frac{p b_{t+1}^{e}}{1+r} .
$$

The latter is larger if and only if

$$
b_{t+1}^{e}>\frac{1+r}{2}\left(e_{A, t}-e_{B, t}\right)\left[(2-p) e_{A, t}+p e_{B, t}\right] .
$$

The utility of citizens with $a=\bar{a}$ and not planning to emigrate from $\mathrm{B}$ is found by inserting (5) into (4)

$$
e_{B, t} \bar{a}+\frac{1}{2} e_{B, t}^{2}+\frac{b_{t+1}^{e}}{1+r} \text {. }
$$


The utility of those high-ability natives planning to emigrate from $\mathrm{B}$ is found by inserting $x_{t+1}^{e}=\tau_{A},(3),(5)$, and (13) into (10), giving

$$
\left[p e_{A, t}+(1-p) e_{B, t}\right] \bar{a}+\frac{1}{2}\left[p e_{A, t}+(1-p) e_{B, t}\right]^{2}+\frac{(1-p) b_{t+1}^{e}}{1+r} .
$$

The latter is higher if

$$
b_{t+1}^{e}<\frac{1+r}{2}\left(e_{A, t}-e_{B, t}\right)\left[2 \bar{a}+(2-p) e_{B, t}+p e_{A, t}\right] .
$$

Proof of Proposition 2.

Notice first that as the change in $p$ is a shock revealed at the beginning of a period, the probability of being mobile is the same for current and all future generations. This implies that the value of the retirement benefits in a flat-rate system and replacement rate in an earnings-related system that the current young generation expects to face are the same as that which will be faced by subsequent generations. Denote the period of the shock by $t$. Then, $x_{t+1}^{e}=x_{t+1+i}^{e}$ and $b_{t+1}^{e}=b_{t+1+i}^{e} \forall i \in \mathbb{N}$. In the country with flat-rate benefits, it also holds that $b_{t}=b_{t+1}^{e}$ as investment in education and migration decisions reach their steadystate values immediately. In the country with earnings-dependent benefits, it need not be that $x_{t}$ would equal $x_{t+1}^{e}$. The reason for this asymmetry is that $x_{t}$ depends on investments in education made in the previous period. By (9) and $x_{t+1}^{e}=\tau_{A}, \partial e_{t}^{A} / \partial p<0$ and by (11) and $x_{t+1}^{e}=\tau_{A}, \partial e_{t}^{B} / \partial p>0$, for those willing to migrate. Notice that those not planning to migrate do not change their investments. The ability thresholds between those planning and those not planning to migrate may change. The threshold change strengthens the effect arising from changed investments by those planning to migrate both before and after the change in $p$.

Proof of Proposition 3.

In any steady-state equilibrium, $x_{t}=\tau_{A}$. Therefore, the welfare of high-ability natives residing in country $\mathrm{A}$ does not change as a result of allowing migration. If high-ability natives from $\mathrm{B}$ want to emigrate to $\mathrm{A}$, then their expected utility must increase by revealed preferences. Similarly, note that when low-ability natives from A want to emigrate to B, then their expected utility must increase by revealed preferences.

To prove that the welfare of low-ability natives living in B may change in either direction, simplify the analysis by assuming that there are two ability types, $l$ and $h$. The innate ability of type $l$ is zero, and that of type $h a_{h}$. The share of type $h$ is $q$. If there is no migration,

$$
e_{A, t}=1-\frac{r \tau_{A}}{1+r}
$$

and

$$
e_{B, t}=1-\tau_{B}
$$

Furthermore,

$$
b_{t}=\tau_{B}\left(q a_{h}+1-\tau_{B}\right),
$$

resulting in utility for low-ability citizens of

$$
\frac{\left(1-\tau_{B}\right)^{2}}{2}+\frac{\tau_{B}}{1+r}\left(q a_{h}+1-\tau_{B}\right) .
$$


With migration, the low-ability natives in country A choose, provided that they are going to migrate if mobile,

$$
\widetilde{e}_{A, t}=(1-p)\left(1-\frac{r \tau_{A}}{1+r}\right)+p\left(1-\tau_{B}\right)
$$

and the high-ability natives in country B choose, provided that they are going to migrate if mobile,

$$
\widetilde{e}_{B, t}=p\left(1-\frac{r \tau_{A}}{1+r}\right)+(1-p)\left(1-\tau_{B}\right)
$$

In an equilibrium with population exchange,

$$
\begin{gathered}
(1+p-2 p q) b_{t}=\tau_{B}(1-q)\left(1-\tau_{B}\right) \\
+\tau_{B}(1-p) q\left[a_{h}+p\left(1-\frac{r \tau_{A}}{1+r}\right)+(1-p)\left(1-\tau_{B}\right)\right] \\
+\tau_{B} p(1-q)\left[(1-p)\left(1-\frac{r \tau_{A}}{1+r}\right)+p\left(1-\tau_{B}\right)\right] .
\end{gathered}
$$

The left-hand side gives total social security expenditures. Total population of the retirees consists of $1-q$ low-ability natives, $q(1-p)$ high-ability natives who remained and $p(1-q)$ low-ability immigrants. The first term on the right-hand side of (A.3) is the revenue from the low-ability natives who all stay, the second term is the tax revenue from the high-ability natives who stay and the third term is the tax revenue from low-ability citizens who migrate from A.

We can next calculate the utilities of high and low-ability natives in a closed economy and in a common labor market, subject to their plans on whether to migrate. Assume that $a_{h}=0.2, q=0.2, \tau_{A}=\tau_{B}=0.2$ and $r=1$. Then allowing for migration with $p=0.2$ results in population exchange, increasing the utility of low-ability natives also in country B. Assume next otherwise identical parameter values, but $a_{h}=0.3$. Now allowing for migration causes low-ability natives in country B to lose.

Proof of Proposition 5.

When $b_{t+1}^{e}=\tau(1-\tau)$ and $x_{t+1}^{e}=\tau$, Proposition 1 implies that all citizens would prefer to migrate from $\mathrm{B}$ to $\mathrm{A}$ and none from $\mathrm{A}$ to $\mathrm{B}$. (To see this, insert first $a=0,(3),(5)$, $\tau_{A}=\tau_{B}=\tau$, and (15) into (A.1) and (A.2).) Both in the transition period and in the new steady state,

$$
\widetilde{e}_{B}=1-\tau+\frac{p \tau}{1+r}
$$

The social security tax revenue in both the transition period and in following periods is given in country A by

$$
T R_{A}=\tau\left(1-\frac{r \tau}{1+r}\right)+\tau p\left(1-\tau+\frac{p \tau}{1+r}\right)
$$

where the first term is the tax revenue from natives and the second term the tax revenue from immigrants. In country B, the social security tax revenue in both the transition period and in following periods is given by

$$
T R_{B}=\tau(1-p)\left(1-\tau+\frac{p \tau}{1+r}\right) .
$$

The total cost of promised social security benefits is in the transition period in country A

$$
T C_{A}^{T}=\tau\left(1-\frac{r \tau}{1+r}\right)
$$


and in country B

$$
T C_{B}^{T}=\tau(1-\tau) .
$$

The total cost of promised social security benefits is in the new steady-state in country A

$$
T C_{A}^{S}=\tau\left(1-\frac{r \tau}{1+r}\right)+\tau p\left(1-\tau+\frac{p \tau}{1+r}\right)
$$

and in country B

$$
T C_{B}^{S}=(1-p) \tau(1-\tau) .
$$

Taking into account the assumption $\tau<\frac{1}{2}$, the results follow as $S_{A, t}=T R_{A}-T C_{A}^{T}$ and $S_{B, t}=T R_{B}-T C_{B}^{T}$ in the transition period and $S_{A, t}=T R_{A}-T C_{A}^{S}$ and $S_{B, t}=T R_{B}-T C_{B}^{S}$ in the new steady-state.

\section{References}

[1] Aaron, H.J. (1966). The Social Insurance Paradox. Canadian Journal of Economics and Political Science 33, 371-374.

[2] Bhagwati, J., and K. Hamada. (1974). The Brain-Drain, International Integration of Markets for Professionals and Unemployment. Journal of Development Economics 1, $19-42$.

[3] Breyer, F. and M. Kolmar. (2002). Are National Pension Systems Efficient if Labor is (Im)perfectly Mobile? Journal of Public Economics 83, 347-374.

[4] Cremer, H. and P. Pestieau. (2003). Social Insurance Competition between Bismarck and Beveridge. Journal of Urban Economics 54, 181-196.

[5] Disney, R. (2004). Are Contributions to Public Pension Programmes a Tax on Employment? Economic Policy 39, 267-311.

[6] Grubel, H.B. and A.D. Scott. (1966). The International Flow of Human Capital. American Economic Review 56, 268-274.

[7] Homburg, S. and W. Richter. (1993). Harmonizing Public Debt and Pension Schemes in the European Community. Journal of Economics 7, 51-63, Supplementum.

[8] Jensen, S.E.H., M.I. Lau and P. Poutvaara. (2004). Efficiency and Equity Aspects of Alternative Social Security Rules. FinanzArchiv 60, 325-358.

[9] Justman, M., and J. Thisse. (1997). Implications of the Mobility of Skilled Labor for Local Public Funding of Higher Education. Economics Letters 55, 409-412.

[10] Kolmar, M. (forthcoming). Beveridge versus Bismarck Public-Pension Systems in Integrated Markets. Regional Science and Urban Economics. 
[11] Lau, M.I. and P. Poutvaara. (2001). Social Security Incentives and Human Capital Investment. CESifo WP 438.

[12] Mountford, A. (1997). Can a Brain Drain be Good for Growth in the Source Country? Journal of Development Economics 53, 287-303.

[13] OECD (2003). OECD in Figures.

[14] Richter, W.F. (2002). Social Security and Taxation of Labour Subject to Subsidiarity and Freedom of Movement. Swedish Economic Policy Review 9, 47-74.

[15] Sinn, H.-W. (1994). How Much Europe? Subsidiarity, Centralization and Fiscal Competition. Scottish Journal of Political Economy 41, 85-107.

[16] Stark, O., C. Helmenstein, and A. Prskawetz. (1997). A Brain Gain with a Brain Drain. Economics Letters 55, 227-234.

[17] Wildasin, D. E. (1999). Public Pensions in the EU: Migration Incentives and Impacts. In A. Panagariya, P.R. Portney and R.M. Schwab (eds.) Environmental Economics and Public Policy: Essays in Honor of Wallace E. Oates (Esward Elgar).

[18] Wildasin, D. E. (2000). Labor Market Integration, Investment in Risky Human Capital, and Fiscal Competition. American Economic Review 90, 73-95. 